\title{
How IT can add Value to logistic sector: Bar code systems and RFID (radio frequency identification) in logistics services
}

ISSN 1857-9973

656.073]:003.295.8:004(100)

\author{
Riste Temjanovski ${ }^{1}$ and Zlatko Bezovski ${ }^{1}$ \\ ${ }^{1}$ Faculty of Economics, "Goce Delcev" University, Stip, Republic of North Macedonia \\ ${ }^{2}$ Faculty of Economics, "Goce Delcev" University, Stip, Republic of North Macedonia \\ riste.temjanovski@ugd.edu.mk13zlatko.bezovski@ugd.edu.mk²
}

\begin{abstract}
Current digital technology can do a lot in terms of improving the visibility of flows of goods and services in logistic sector. Managing and locating important assets is undoubtedly a key challenge for almost any business. Business is time interrelated and shortening the time for certain operations in business is related to the profit or loss of funds. Time spent searching for critical equipment can lead to expensive delays or down time, missed deadlines and customer commitments, and wasted labor. RFID asset management is now a well-known solution for identifying and tracking valuable assets. An RFID asset tracking system uses electromagnetic fields to transmit data from an RFID tag to a reader. But what is RFID really? RFID is an acronym for "radio frequency identification" and refers to a technology where digital data encoded in RFID tags or smart labels are captured by a reader via radio waves, and used in this case for RFID asset tracking and tools and equipment management. Existing technologies now and in the future, play and will play an important role in modern distribution sector for the movement of their products or raw materials. In fact, the benefits of specific technologies, such as identification of the radio - frequency (RFID) and Global Positioning Systems (GPS) are already in use by leading distribution companies.

Existing technologies now and in the future, play and will play an important role in modern distribution sector for the movement of their products or raw materials. In fact, the benefits of specific technologies, such as identification of the radio - frequency (RFID) and Global Positioning Systems (GPS) are already in use by leading distribution companies. Technological changes in communications between the devices themselves, goods and vehicles have helped to significantly improve the quality of services, advantages that every business must take this advantage.
\end{abstract}

Kew words: Supply chain management, logistic sector, bar code systems, RFID, IT

\section{Introduction}

The storage system as part of the logistics management system should ensure the storage of product stocks and the protection of their usable characteristics during the period of time they are in stock. According to the Council of Supply Chain Management Professionals [1] logistics is "part of the supply chain process that plans, implements and controls the efficient, effective 
forward and reverses flow and storage of goods, services and related information between the point of origin and the point of consumption in order to meet customer's requirements."

Of course, product stocks are not kept exclusively in warehouses, because certain stocks are found in the production process and in sales facilities, just as warehousing systems do not have the exclusive function of storing stocks. The various storage facilities (warehouses, inventory stocks, distribution centers, etc.) have other tasks and functions.

Storage is one of the most complex components of the logistics system because storage issues involve several decisions related to the following: [2]

1) where the location of the storage will be located, whether at the place of consumption, at the place of production, ie some third solution;

2) whether to build their own warehouses or to leave that function to the trade, ie. to use public warehouses or to use alternative distribution systems;

3) how many warehouses to build;

4) what size of the warehouses and other objects of the physical distribution to be determined, etc.

Different criteria can be used in selecting the storage location.

1) criterion of market-oriented location of the warehouses, which strives for the warehouse to be as close as possible to the buyers, whereby the stocks and the time of their storage are reduced to the smallest possible measure. This method is very suitable for products that do not suffer a long period of storage, such as food products, etc;

2) criterion according to which the warehouses are production oriented, i.e. they are located near the production facilities.

3) combined criterion, where the location is determined depending on the proximity of the buyers and the proximity of the production facilities.

Current digital technology can do a lot in terms of improving the visibility of flows of goods and services in logistic sector. Managing and locating important assets is undoubtedly a key challenge for almost any business. Business is time interrelated and shortening the time for certain operations in business is related to the profit or loss of funds. Time spent searching for critical equipment can lead to expensive delays or down time, missed deadlines and customer commitments, and wasted labor. It is more cost-effective or easier to automate the processes and ensure that the company has accurate and timely inventory knowledge at your fingertips - ensuring that meet the regulatory and customer obligations.

Companies have traditionally addressed this problem by managing assets using serial numbers and spread sheets or tracking equipment with barcode labels. However, both of these methods require a significant amount of manual labor. One way to quickly improve asset management is by utilizing radio frequency identification (RFID) technology to automatically track those assets. RFID asset management is now a well-known solution for identifying and tracking valuable assets. An RFID asset tracking system uses electromagnetic fields to transmit data from an RFID tag to a reader. But what is RFID really? RFID is an acronym for "radio frequency identification" and refers to a technology where digital data encoded in RFID tags or smart labels are captured by a reader via radio waves, and used in this case for RFID asset tracking and tools and equipment management.

\section{Radio-frequency identification (RFID}

Radio Frequency Identification (RFID) has emerged as one of the most revolutionary tools in supply chain and logistics. Although high technology is still considered young and emerging, it is based on electronic devices (computers and internet networks), and therefore, major breakthroughs are not only natural but are expected. This newer version of the technology was fueled primarily by the need for lower-cost tags and quick operations. "Smart labels" represent the next generation in RFID for industries that want to primarily identify and track 
millions of items at a low cost. The technology is capable of helping organizations cut down on their expenses and hence become more competitive in the market. RFID uses radio frequency electromagnetic fields for data transfer. RFID stands for "radio frequency identification". It's a technology that captures digital data encoded in smart labels and RFID tags through a reader via radio waves. RFID serves a similar purpose to that of bar code or a magnetic strip of an ATM card where data from a label or tag is captured by the device and then later stored in the database. However, RFID works better than barcode and ATM magnetic strips. The most significant advantage of using RFID over barcode is that it doesn't need to be placed or positioned relatively to the scanner.

The radio frequency identification device (RFID) was first developed by the military as a radar transponder technology in order to discriminate between friends and foes.[3] Nowadays, a RFID tag is better known as a small object that can be attached to or incorporated into a product, which stores a unique ID number and can be sent via radio frequency. It can also take the form of a label and blend in the current pallet labelling process. The basic idea of RFID is to get away from line of sight scanning of previous barcode systems for proximity scanning through radio frequency. As a tag passes through a reader or gets interrogated by a portable reader, it retrieves an identification code, which is used to query the system to get detailed information such as content history.

Most of the information in the next generation supply chain is generated by machines, e.g., sensors, radio-frequency identification (RFID) tags, meters, actuators, and GPS. They are applied to the tracking of information flows and the collection of data on products or services, capital, and other important elements in the supply chain to achieve information-driven endtoend processes that facilitate information sharing and decision analysis in an enterprise.[4] In its simplest form, an RFID system consists of a tag (attached to the product to be identified), an interrogator (i.e., reader), one or more antennae attached to the reader, and a computer (to control the reader and capture the data).[5]

1. Hardware selection; fixed readers/antennas and hand-held readers

2. RFID tags

3. RFID reader software

4. Asset register system for asset tracking data

RFID systems can be classified by the frequency used and whether the system is active or passive. Passive tags are powered by radio waves (an electromagnetic field) created by a reader and transmitted via its antennae. The passive tag will remain powered only while it is within the read field. Once a passive tag leaves a read field, it stops transmitting and is essentially dormant. While in the read field, the powered tag will respond to the reader by reporting the data contained on the tag's chip. Unlike passive tags, active tags have an internal battery which powers the tag. Because active tags have their own power source, they do not need a reader to energize them; instead, they can initiate the data transmission process.

Table 1. Asset tag types and applications 


\section{Asset tag types and applications}

\begin{tabular}{|c|c|c|c|c|}
\hline Tag type & Asset \$ value & Tag cost & Advantage & Disadvantage \\
\hline Barcode & Low value & Low & Minimal cost & No tracking ability \\
\hline RFID & Modium - High & Medium-High & Basic tracking & Tracking at certain \\
points
\end{tabular}

Active tags have a longer read range, can store more data, and can perform some processing functions, but, due to the battery, have limited lifetimes, are larger in size and are more expensive than passive tags. Active RFID tags are most frequently found in defence or military operations, yet also appear in technologies such as road tolls, where tags are linked to a prepaid account, enabling drivers to pay tolls by driving past a reader rather than stopping to pay at a toll booth.

In the spirit of contemporary technological advancements, companies have developed many approaches to monitoring and managing the movement of goods. According to Wood, Reiners and Pahl [6] identification of materials is crucial in three main logistics processes:

(1) the tracking and handling of materials during logistics processes,

(2) the tracking and consolidation components or packages from multiple parties including third Party Logistics (3PLs) providers, and

(3) the monitoring and handling of materials at point of sale (POS) in the retail environment.

Initial attempts to identify inventory related to providing an identification code to different batches, which may take the form of a physically adhered label with a job or batch number written on it.

\section{Bar code systems and modern information technology}

Bar code systems are modern information technology that plays a particularly important role in collecting, processing and exchanging information. Bar coding is actually the electronic scanning and identification of certain logistics information that is on the product packaging. This information is of particular importance to the production, warehouse or sales logistics unit as it closes the information cycle for movement and current state of the product. Bar coding is part of an information system that allows sales and payments to be made faster, invoices are easier to prepare, and an adequate volume of stocks is maintained. Bar codes contain a huge amount of data and therefore the development of such technology is constantly growing. Today, bar codes also play the role of marketing tools. 


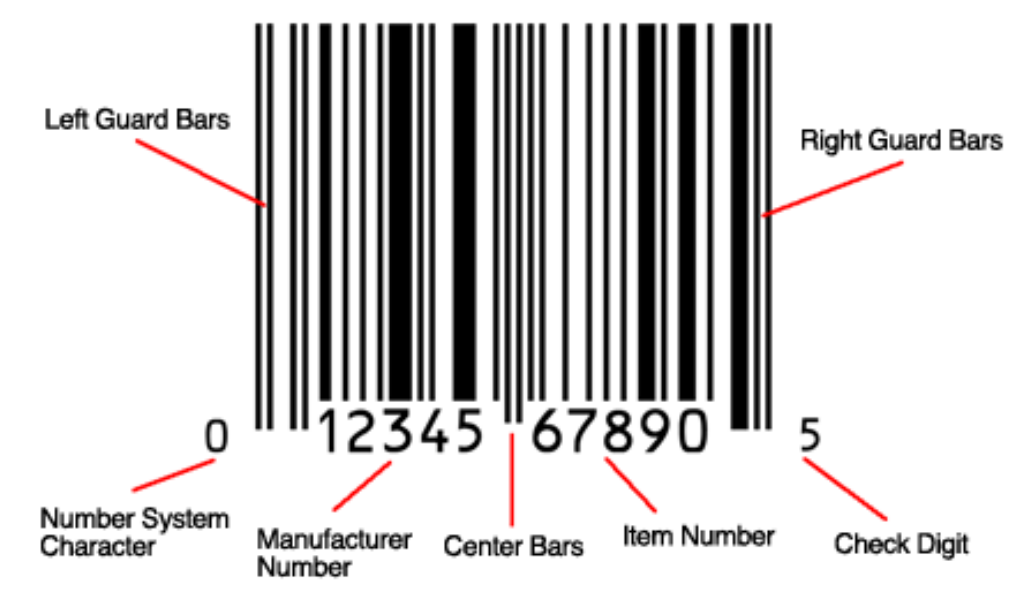

Figure 2. The product bar code for sale

A barcode is "A machine-readable code in the form of numbers and a pattern of parallel lines of varying widths, printed on and identifying a product." Barcode systems help businesses and organizations track products, prices, and stock levels for centralized management in a computer software system allowing for incredible increases in productivity and efficiency. These can be interpreted using an optical reading device that captures the image, extracts the information, and converts it into useable data (i.e., unique identification number). It improves the speed and accuracy of reading labels and identifying items and reduces error rates.

The lines and patterns on a barcode are actually representations of numbers and data and their development allowed basic information about a product to be easily read by an optical scanning device, a barcode scanner, and automatically entered into a computer system. This vastly reduced the time it took to record such information and eliminated the potential for human data entry error. Barcodes started out with simple 1 dimensional designs, consisting of basic black lines that could only be read by specially designed barcode scanners. However, today barcodes come in many shapes and sizes and a wide range of designs and many can even be read by mobile phones and other devices.[7]

Visual examples of the various barcode types:[8]

for GTIN-13 numbers

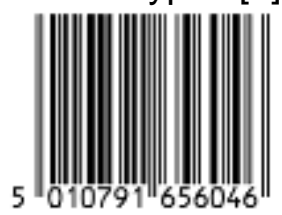

for GTIN-12 numbers

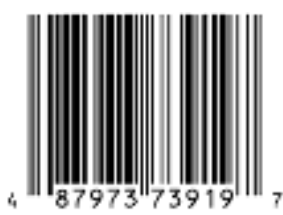

(including GS1-128)

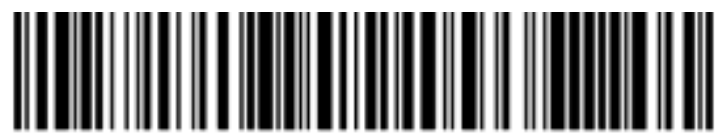

(10) $123456(8020) 198798787$ 
for GTIN-14 numbers

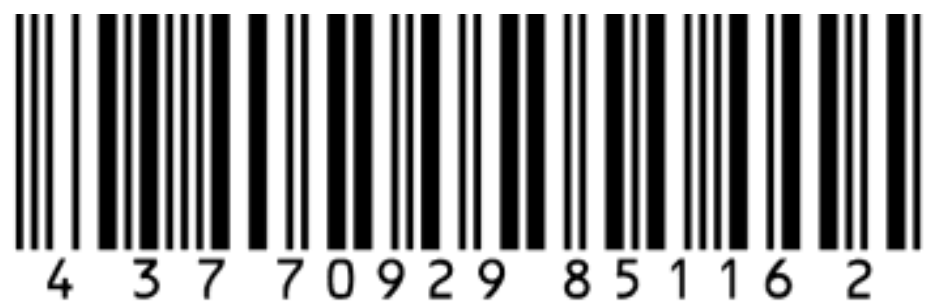

Intelligent Mail numbers

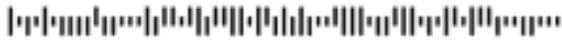

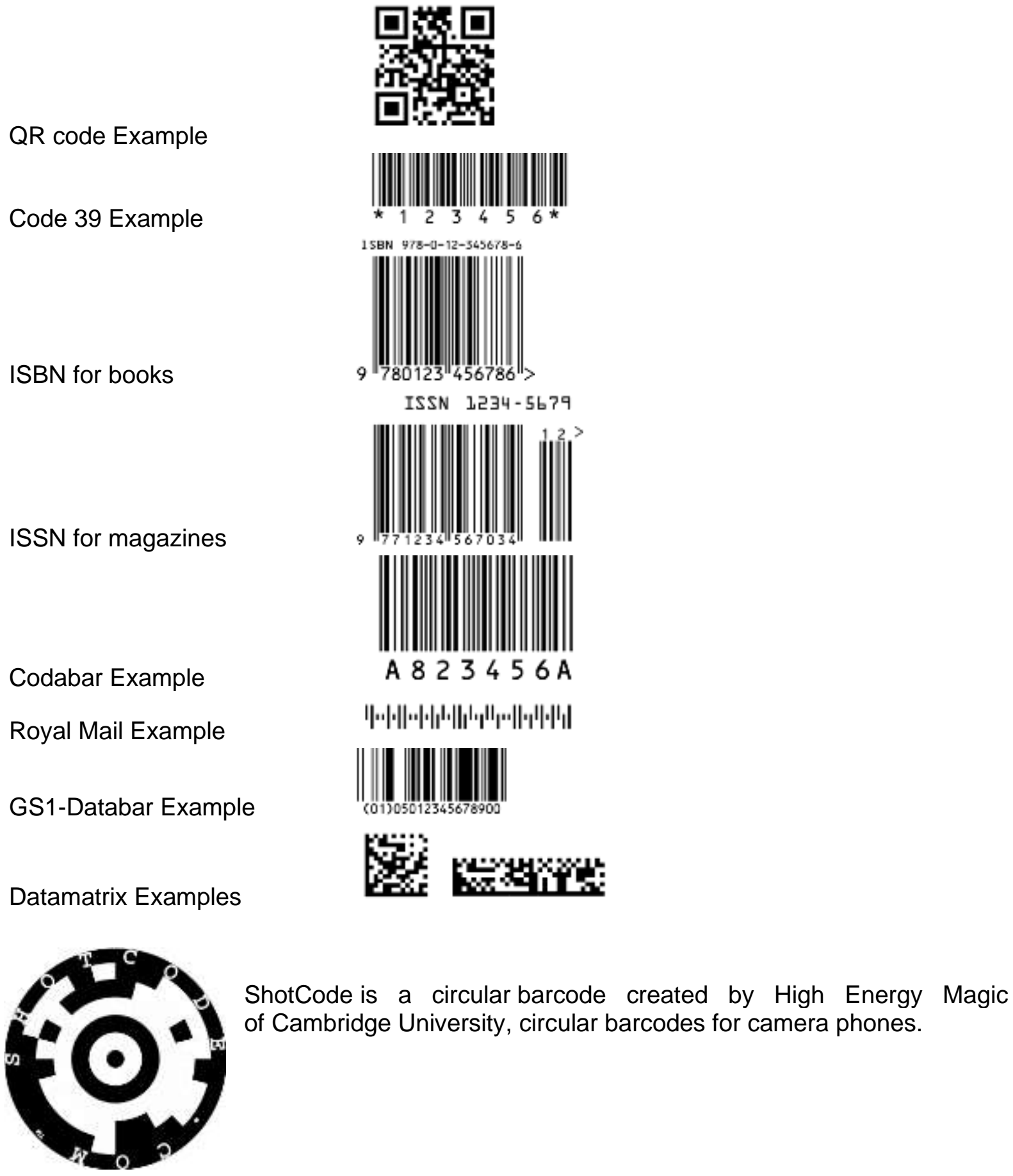




\section{Bar code systems and RFID: benefits and weaknesses}

The use of bar-coded technology could provide a good alternative to the current manual system without the costly RFID infrastructure requirement. RFID will generate the most benefit in a dense supply stream where there is a shortage of logistic labor or when its cost is considerable. It is also highly desirable for high-end costly items such are specialized engineering parts that require enhanced tracking given the value of items. [9]

RFID belongs to a group of technologies referred to as Automatic Identification and Data Capture (AIDC). AIDC methods automatically identify objects, collect data about them, and enter those data directly into computer systems with little or no human intervention. RFID requires costly equipment whether it be a software or hardware. RFID methods utilize radio waves to accomplish this. At a simple level, RFID systems consist of three components: an RFID tag or smart label, an RFID reader, and an antenna.

Unlike barcodes which scans information from one item to another and require scanning (this means that manual labor is required in reading each of the boxes), RFID can examine the goods hidden behind other products. Identifying products using RFID is quicker than barcode scanning or manual entry of product details. Warehousing companies prefer RFID because of its accuracy in data transmission and hence the elimination of human errors. Using RFID in the warehouse promotes immediacy because the management software is updated in real time.

RFID compared to bar codes [10]

- Similarly - a support tool to automate processes and to improve operations management.

- Reduces labor, eliminates human errors.

- Puts a wealth of data at your fingertips.

Different, in that:

- Tags can be embedded and hidden with no need for line-of-sight. They can be read through wood, plastic, cardboard, any material except metal.

- Tags can re-programmed on-the-fly.

- Applicable in harsh environments, such as outdoors, around chemicals, moisture and high temperatures.

Dolgui and Proth [11] highlight a few more significant differences between RFID and bar code:

$>$ Unlike bar codes, data are not gathered manually and, since companies have a great number of products, using RFID leads to a drastic reduction in workload.

$>$ When using a bar code, the operator has to scan the items one by one, while the RFID reader can automatically receive information from the tags.

$>$ RFID scanning can be done at greater distances than bar code. The scanning distance of RFID depends on the type of system as explained hereafter.

$>$ The constraints that apply to the positioning of the tags are much weaker than the constraints to satisfy when bar codes are concerned. Tagged objects can be read in different orientations at high speed. Orientation sensitivity depends on antenna design.

$>$ Tags can store more data than bar codes.

$>$ RFID readers can communicate with multiple tags. As a consequence, it is possible to capture the information concerning an entire shipment.

The very popularity of barcode in many areas of the supply chain has clarified its limitations. Conventional barcodes can only hold a small amount of information, typically around 20 characters, and can't be reprogrammed. They are susceptible to damage while en route, and always require line-of-sight to be read successfully. These are limitations that RFID tags have overcome. 


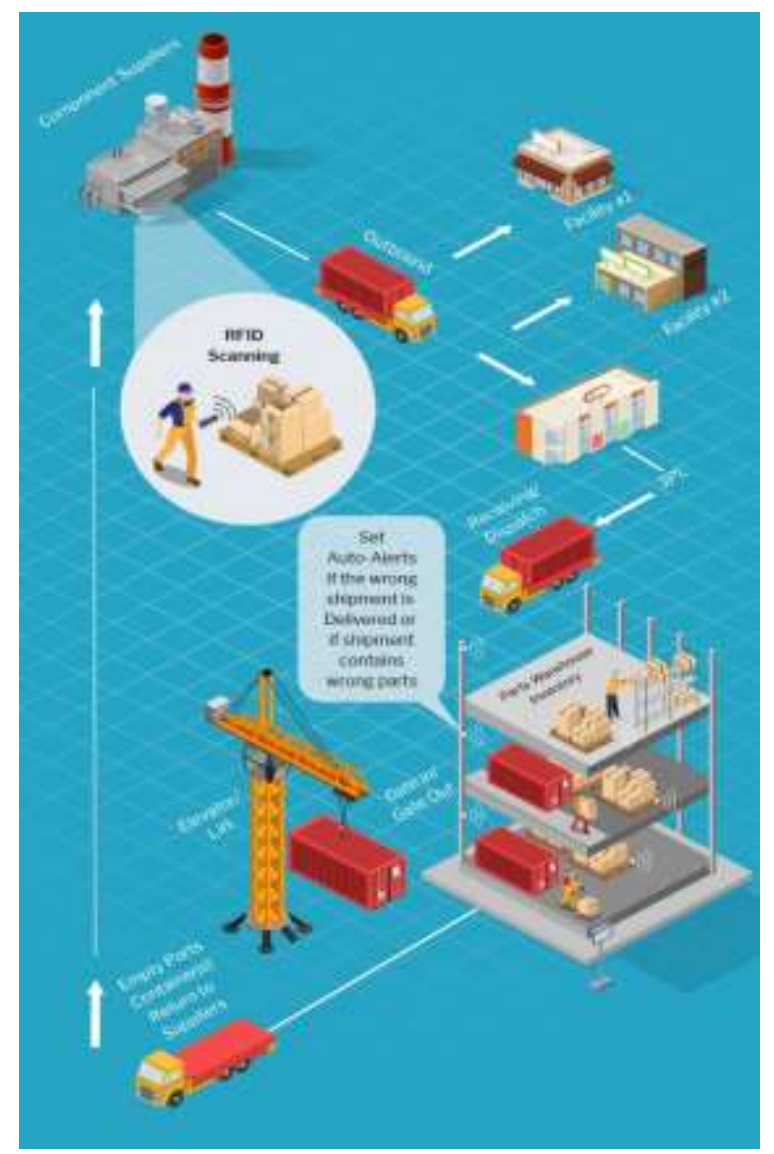

Figure2. RFID model in logistic [12]

According to Sunil [13] the main significance of RFID in supply chain management and logistics is that it provides a quantum leap in the improvement of various management methods thus providing solutions to industries facing low margins. One of most advantages of RFID for onboard logistics is labor reduction and potential savings in offering real time visibility, hence reducing the labor required in tracking and tracing, that is sufficient to justify implementation of tags. RFID can provide direct benefits such as the possibility of real time depletion of stock. RFID technology could be very critical in the prevention of data inaccuracies. It prevents companies from collecting incorrect or outdated data used lading bills and invoices. This helps to prevent delivery errors and lost sales. With the incorporation of blockchain technology, data security can be improved in more details. The decentralization of the data allows the organizations in the supply chain and logistics industry to keep track of the events in real time, hence ensuring traceability and accountability.

Below are ten benefits that result from using this technology:

1. More flexibility and intelligence in the process to improve service levels

2. Improve the quality and transparency of data across the supply chain

3. Increase the accuracy of and reduce the time spent taking inventories

4. Reliable track and trace in challenging physical environments

5. Allows you to check shelves, boxes, and pallets on top without any eye contact.

6. Increase efficiency and cut down on rework

7. Reduces the total cycle time order until the goods delivery (provide direct benefits such as labor reduction and potential savings in offering real time visibility)

8. Increased speed and agility in locating materials. 
9. Easy monitoring of all logistics operations along with increased security (mitigate risk, theft and loss)

10. Reduces the errors made in deliveries of customers' orders.

With the growing demand for the supply of consumable products in the retail business, undoubtedly, agility is a primary requirement for the attainment of maximum results. RFID applications can automate the collection of information about the movement and location of assets, components, stock or other items. After retrieval, the product becomes viable for shipping the checking, packing, and loading into the allocated transport unit. All the information required is securely stored to the payment stage where it is rendered upon delivery. Without RFID, the retail and supply chain services would not achieve progress in its services and payment systems. It should be noted that effective use requires significant investment in infrastructure to support the introduction and implementation of a continuous tracking of RFID tags.

Existing technologies now and in the future, play and will play an important role in modern distribution sector for the movement of their products or raw materials. In fact, the benefits of specific technologies, such as identification of the radio - frequency (RFID) and Global Positioning Systems (GPS) are already in use by leading distribution companies. Technological change in communications (such as satellite global positioning systems that maintain communication with the carrier) helped to significantly improve the quality of services.[14]

\section{Summary}

Most of the information in the next generation logistics and supply chain companies is generated by machines, e.g., sensors, radio-frequency identification (RFID) tags, meters, actuators, and GPS. They are applied to the tracking of information flows and the collection of data on products or services, capital, and other important elements in the supply chain to achieve information-driven end-to-end processes that facilitate information sharing and decision analysis in an enterprise.

The use of bar-coded technology could provide a good alternative to the current manual system without the costly RFID infrastructure requirement. RFID can provide direct benefits such as labor reduction and potential savings in offering real time visibility, hence reducing the labor required in tracking and tracing, that is sufficient to justify implementation of tags. RFID applications doing services this more quickly, whilst reducing costs and with greater accuracy and reliability than is possible with manual methods and with more detail than can be obtained from techniques such as bar-coding. Data collection can be a by-product of other activities, eliminating the need for effort in form filling. It is also highly desirable for high-end costly items such are specialized engineering parts that require enhanced tracking given the value of items.

To improve the benefits of bar code and RFID technology, it is necessary to extend the cooperation with logistics, storage, and warehouse centers. In this context, one could use the tags for carrying information from production to warehousing and logistics to facilitate their business. Among the expected benefits, there is storage optimization in warehouses and easier transport programming thanks to a more detailed and precise information that become available in real time.

\section{References}


1. Council of Supply Chain Management Professionals. (2020). CSCMP Supply Chain Management Definitions and Glossary: CSCMP's Definition of Logistics Management . Retrieved from https://cscmp.org/CSCMP/Educate/SCM Definitions and Glossary of Terms.aspx [02.09.2020] 2. Јаќовски Б., Шулеска Ц.А.(2008): Маркетинг менацмент. Скопје: Европски универзитет, 2008. стр.270-275.

3. Veronneau S., Roy J.: RFID benefits, costs, and possibilities: The economical analysis of RFID deployment in a cruise corporation global service supply chain, International Journal of Production Economics - 122 (December 2009) 692-702.

4. Zhao J., Meng J., Feng B.: Smarter supply chain: a literature review and practices. Journal of Data, Information and Management (2020) 2:95-110. p.97 https://doi.org/10.1007/s42488-020-00025-z

5. Hardcat. (2019, February 7). RFID asset management - expectations vs reality. Retrieved from https://www.hardcat.com/rfid-asset-management/ [02.09.2020]

6. Wood, L. C., Reiners, T., \& Pahl, J. (2015). Manufacturing and logistics information systems. In M. Khosrow-Pour (Ed.), Encyclopedia of Information Science and Technology (3rd ed., pp. 5136-5144). Hershey, PA: Information Science Reference. DOI: 10.4018/978-1-4666-5888-2.ch507. p.2.

7. Wasp Barcode Technologies. (2020). Barcode: The Ultimate Guide to Barcodes. Retrieved from https://www.waspbarcode.com/buzz/barcode [19.06.2020]

8. Computalabel. (2020). Code 128 / GS1-128 Barcode Examples. Retrieved from http://www.computalabel.com/mbcSymList.htm [19.06.2020]

9. Véronneau S., Roy J.(2009): RFID benefits, costs, and possibilities: The economical analysis of RFID deployment in a cruise corporation global service supply chain. Int. J. Production Economics 122 (2009) 692-702 DOI: 10.1016/j.ijpe.2009.06.038 .

10. Supply Chain Market. (2020). The Cutting Edge of RFID Technology and Applications for Manufacturing and Distribution. Retrieved from https://www.supplychainmarket.com/doc/the-cuttingedge-of-rfid-technology-and-appli-0001 [19.06.2020]

11. Dolgui A., Proth J.M.(2008): RFID technology in supply chain management: State of the art and perspectives. Proceedings of the 17th World Congress The International Federation of Automatic Control Seoul, Korea, July 6-11, 2008. pp. 4464-4465

12. Mansuri, S. (2020). Complete guide on RFID and its applications in supply chain management and logistics. Retrieved from https://www.peerbits.com/blog/rfid-applications-in-supply-chain-managementand-logistics.html [19.06.2020]

13. Sunil K (2019) How Radio Frequency Identification (RFID) can revolutionize the Supply Chain Management. J Inf Technol Softw Eng. 9:252. p. 2. Doi: 10.35248/2165-7866.19.9.252

14. Temjanovski R., Marjanova Jovanov, T.: Information Technology and Distribution Channels: Current Trends. Journal of Economics. Vol.1, No.1 (2016), ISSN 1857-9973.p.4. 